\title{
Evaluation of Scientific and Practice Approaches to Soft Skills Requirements in the ICT Project Management
}

\author{
Malgorzata Pinkowska ${ }^{1}$ and Bogdan Lent ${ }^{2,3,4}$ \\ ${ }^{1}$ Department of Computer Engineering, Faculty of Engineering, Kasetsart University, Bangkok, \\ Thailand \\ ${ }^{2}$ Department of Management and Command, National Defence University, Warsaw, Poland \\ ${ }^{3}$ Department of Economics and Administration, University of Applied Sciences, Bern, Switzerland \\ ${ }^{4}$ Faculty of Telecommunications and Electrical Engineering, University of Technology and Life \\ Sciences, Bydgoszcz, Poland
}

\begin{abstract}
Majority of products and services in today's technologically advanced and global world is developed in form of projects. ICT (information and communication technology) research and practice confirm that success of those projects depends on three equivocally relevant areas: technology, management process and people. The last, as proven in numerous surveys and research, is the main cause of failure and challenge of the ICT projects. Project manager skills to handle humans are essential to those endeavours.

This paper examines trends in required soft skills for ICT project managers, reflecting state-ofthe-art in the field. The skills identified in a careful survey of 219 job advertisements for ICT project managers in Switzerland, Poland and Thailand are compared with the soft skills identified in 27 journal and conference publications as well as further 46 monographs and standards on project management. For evaluation purpose authors adopted the L-Timer ${ }^{\mathrm{TM}}$ process based mental model of project management.

Whereas science considers leadership skills and communication capabilities as most important one, practice calls for communication and leadership in reverse sequence, followed by the team management, first. The processes of Human Resource, Conflict and Self Management are underrepresented in the advertisements. While Switzerland represents weighted approach, Poland focuses on team management capability, while Thailand demands leadership qualities of prospective project managers. The cultural roots evaluation and inter-cultural differences reflected by the conclusions of this paper are further research objectives of the authors.
\end{abstract}

Keywords: Project manager, soft skills, human factor, L-Timer ${ }^{\mathrm{TM}}$

\section{Fundamental Skills of Project Manager}

Within the next five to ten years project management is viewed by Collette (2006) as one of the five top "hot skills" around the world. According to Pant et al. (2008) the job of the ICT project manager is demanding, complex, varied and requires the juggling of several issues concurrently. The skills required to master the project management are cross-over of the information technology (IT), management and social sciences (Fig. 1).

Copyright (C) 2011 Malgorzata Pinkowska and Bogdan Lent. This is an open access article distributed under the Creative Commons Attribution License unported 3.0, which permits unrestricted use, distribution, and reproduction in any medium, provided that original work is properly cited. Contact author: Malgorzata Pinkowska, e-mail: malgorzata.pinkowska@bspp.pl 


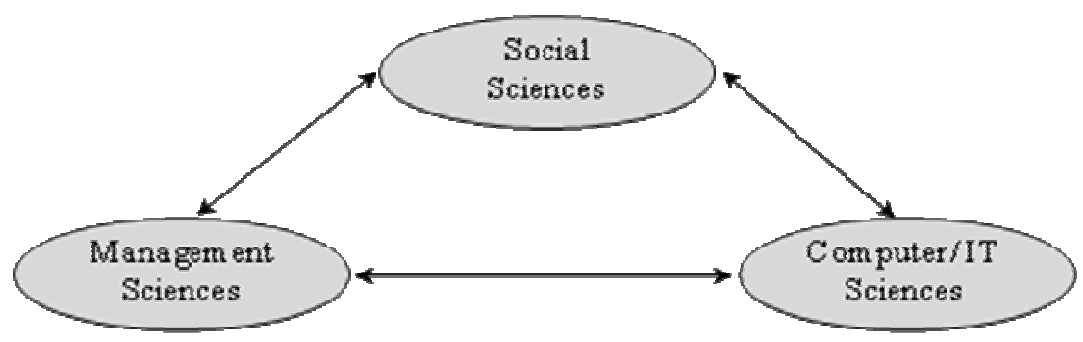

Fig. 1. Project Manager Skills Areas

According to Strang (2003), managing projects successfully requires a mixture of skills including interpersonal ability, technical competencies and cognitive attitude, along with the capability to understand the situation and people and then dynamically to integrate appropriate leadership behaviours.

Several different theories about project success factors are brought up (Archibald, 1992; Blaney, 1989; Duncan, 1987; Moriss \& Hough, 1987; Powers \& Dickson, 1973, Redmil, 1990; Shenhar et al , 1996; Gillard, 2009) and the discussion about what is more important: hard technical skills or soft social skills has broken out (Suikki et al, 2006; Thieme et al, 2003; Kerzner, 2003; Toney \& Powers, 1997; Waterdige, 1995; Wong, 2007).

Whatever arguments are used, all authors agree, that:

- soft skills have to be taken into consideration in successful project management and

- project leader needs to master special soft skills, which are necessary for successful team management (Martin \& Tate, 2001).

At the same time MillwardBrown (2005) report pinpoints that students of the universities, especially technical universities, many of whom later continue their professional career as project manager, have no or not enough opportunities to exercise those essential skills.
Cowie (2003) concludes that the success of a project rests on the understanding of people and management related aspects, and that as such these should also be included in project management training courses along with the technical skills needed. Lent (2009) implements this view in their courses. Sukhoo (2005) pinpoints that Companies like Polaris, Sun Microsystems and Mastek recognized the importance of human factor and adjusted subsequently their recruitments requirements and trainings for project managers. Several universities and training organisations base their education on Body of Knowledge of PMI (2004) and IPMA (2006) Baselines, both providing reasonable mix of competences demanded in project management.

\section{What are the Soft Skills}

There are still a wide number of terms used to describe the similar understanding of "soft skills", with the lack of clarity and definition. The same soft skills are variously referred to by various authors in such phrases as:

- soft factors (Caupin et al, 1999; Wohlin, 2005),

- interpersonal skills (Gillard, 2009; PMI, 2004),

- people skills (Flannes, 2004),

- personal skills (Murch, 2001),

- social skills (Alam et al, 2010), 
- critical skills (Lee et al, 1995),

- human skills (Pant \& Baroudi, 2008),

- key skills (Simpson, 2006), etc.

The term "soft skills" seems to have two sources of origin.

First source of origin Simpson (2006) identified with employers and recruiters, who are increasingly identifying the need for non-technical and non-traditional skills, and subsequently use the term to describe the personality traits of the individuals and how they interact with others.

The second origin arises from the need to describe the outcomes of any endeavour, which are not easily visible, quantifiable, and measurable. Dewson (2000) describes "soft skills" as those skills required to achieve "soft outcomes", and "soft outcomes" as outcomes which are "difficult or impossible" to measure. Wohlin (2005) follows this view in project management evaluation and refers to all non-technical aspects, which are difficult to quantify, as "soft factors".

Most of the authors use term "soft skills" to describe jointly all or parts of the aspects like qualification of project personal, social behaviour in conflicts, motivation to work and management style. The clear definition of the used term "soft skills" is generally missing.

For the purpose of the research pursued by the authors, the term "soft skills" is used to describe all interpersonal skills, which contribute to higher efficiency of the execution of the human factor related processes of project management as presented in the subsequent chapter.

\section{Soft Skills Classification - Human Factor Processes in Project Management}

While considering the skills needed, one asks himself first "what for"? Generally, we say, that there is certain action to be performed and appropriate skills allow doing it in more or less efficient way.
The process model of project management and its components: sub-processes and single tasks proved to be helpful in identifying and allocating the demanded skill. Some skills are useful in several processes. Their recurrence is useless from the point of view of the targeted summary of all skills. Therefore, the skill, useful in more than one process, is assigned arbitrary to only that process, for which particular skill is essential in fulfilling process goal.

The international standards differentiate in their approach and identification of the project management processes. The mental model of project management processes pursued by the authors, distinguishes two groups of the processes:

- measurable, "classical" project administration processes like planning, controlling, change management, risk (called by DeMarco (1999) "formulaic parts") and

- human factor related processes, where management impact is yet to be quantified (Lent \& Pinkowska, 2006).

Both groups are bound by Lent (2003) into the management system of L-Timer ${ }^{\mathrm{TM}}$. The L-Timer $^{\mathrm{TM}}$ system in comprehensive and complete way comprises all project management processes as far as state-of the-art allows concluding.

In further evaluation of the "soft skills" the human factor related processes of the LTimer $^{\mathrm{TM}}$ system are used as a common denominator and basis for the evaluation of various contributions.

\section{HRM: Human Resource Management (Process)}

Project manager, performing the HRM process, generally targets the best assignment of team members and formal roles taking the informal roles, which emerge in a team, under consideration (Belbin, 2010). The most important questions according to Lent (2005) which project manager has to answer during this process are: 
- Whom does he need to the project?

- What does each member of project team expect, what are his needs?

- Do the people match with each other?

- How can he verify, whether his or his team expectations are fulfilled?

\section{TM: Team Management (Process)}

The goal of team management process is to ensure the best possible efficiency of the complete project team measured against yielded performances, staff commitment, client satisfaction and process improvement. The efficiency is determined by mutual trust, built on knowledge of the personalities and smallest details of daily life of each team member. It is achieved in the process of group integration.

According to Turner (1993) there are four stages in the integration process:

- Forming (pretending to get on or get along with others);

- Storming (letting down the politeness barrier and trying to get down to the issues even if tempers flare up );

- Norming (getting used to each other and developing trust and productivity);

- Performing (working in a group to a common goal on a highly efficient and cooperative basis.

Pinkowska (2006) pinpoints that an appropriate team management has significant impact on team performance and productivity.

\section{CFM: Conflict Management (Process)}

There is no team where sooner or later a conflict situation does not occur. Conflict dramatically reduces the efficiency of a team up to the point where a real crisis (no one believe in positive outcome any more) reduces the productivity to practical zero.
Project managers shall identify potentials of conflict in project teams and between team members and persons relevant to the project from the outside, further undertake actions to solve conflicts with suitable methods and technologies and finally secure the sustainability of the solution.

Conflict solution means weighting up possible strategies: shall I behave cooperatively or go militantly towards a confrontation? With the same possibilities for other conflicting party we get four combinations commonly deployed and known in gaming theory.

\section{COM: Communication Management (Process)}

Effective communication is one of the key motivators in a project. Melymuka (2006) claims that $75 \%$ of all problems left after all "administrative" measures are applied, are due to the missing communication between the team members and the stake holders.

Communication comprises project marketing and unsolicited information, both exchanged ambiguously within the project team as well as with the outside world which is relevant to achieving project goals.

Sending a message does not necessarily means that the other side understood us exactly the way we wanted. Beside, the interpretation of the message in a context, which is often unknown to the sending party, may result in a complete adverse picture compared to that, which was originally sent. Proper communication skills are crucial here.

\section{SM: Self Management (Work \& Life Balance)}

Self - Management contributes towards reaching the project objectives by developing the personality, personal attitude, capability and personal objectives towards successful work and life balance. It is a personal process of project managers, and shall be a process of each team member, too. 
If we can handle our own resources well: time, health, intellectual capability, we can be expected to handle the complexity of a project. The emotional stability: a balance between the social and personal views on one side and positioning between the perception and behaviour on the others is decisive in trust build-up between the team members. A positive attitude: "I am ok you are ok" helps to preserve the balance and deploy efficiently the intrinsic motivators, to the benefit of the project.

\section{L: Leadership}

Leadership is a particular process where skilful and conscious control of the behaviour of team members, targets initiation of specific actions to be taken by the team members.

Motivating people is a key activity of a leader. According to Nash (2004) leaders distinguish themselves by:

- strong will to win,

- focus on achieving the results,

- establishing the culture of readiness for changes,

- creating an atmosphere of trust.

Leader demonstrates his skills by dealing with uncertainty. According to Thomas Mengel (2008) the sense making intelligence allows leader to take reasonable risk and yet prove right in various unpredicted project occurrences, with deep impact on team perception.

Project manager is perpetually engaged in each process, i.e. performing some actions like e.g. choosing team member to fulfil a specific role shall be periodically reviewed and adjusted if chosen person does not meet the expectations. Nevertheless, in the research study by Pinkowska (2006) the number of all actions is as vast as the number of "soft skills" needed to perform these actions. As human can handle only a limited number of activities, a role system with priorities within the individual roles and tasks have to be settled.

\section{Soft Skills - Scientists and Practitioners Point of View}

In order to identify the set of "soft skills", authors proceeded first with an analysis of the relevant scientific and research papers. In the second step the content analysis of related job advertisements published by companies which intend to hire ICT project manager, has been conducted.

Both results have been validated, evaluated and compared.

Challenging to the authors was differential level of skill description. The process model, described by Pinkowska (2010), and its components: sub-processes and single tasks proved to be helpful in allocating properly each individual skill. The 78 soft skills, which were extracted from the monographs and standard as well as journals and conference proceedings, and single 38 items from the advertisements, were allocated along the tasks to be performed.

Generally both groups - scientists and practitioners - named the skills using either broadly applicable expressions on a very high level of process or particular skill name, without context and criteria why this particular has been chosen from the set of related skills.

Consequently, those process-level relevant skills are listed as first in each process, and are printed in bold in Table 2. The definition of each process is given in Chapter 3 here above. The less general skills, being part of the process-level skills are at lower positions in the Table 2. Certain overlapping is unavoidable. This is taken under considerations in the drawing of the conclusions.

\section{Soft Skills as Seen by the Scientists}

A literature survey was conducted with the aim of soliciting the soft skills which are considered as essential to the successful project manager profile. 
We distinguished two groups of the reviewed contributions, both focused on project management:

- Journals and conference publications, which are considered to report newer and up-to-date results.

- Monographs and standards, which can evaluate the subject more thoroughly and broadly, however usually lack some actuality.

27 journals and conference proceedings and 46 monographs and standards strictly related to project manager skills, underwent the analysis.

The content analysis of both groups allowed identifying 78 soft skills. They are listed in Table 2, separately for each group: "Journal" for the skills named in journals and conference publications and "Mono" for monographs and standards' results. The skills are further grouped along the tasks of each of the six human factor related LTimer $^{\mathrm{TM}}$ processes presented above.

Nuances in evaluating the level meant by the author and wording differences in various publications have been carefully weighed against each other.

\section{Soft Skills as Seen by the Practitioners}

In evaluating the practitioners point of view, a selection of countries which are taken under considerations, has been done. The access of the authors to the sources and linguistic capabilities to analyse the content were one criterion. The other is the comparability of the economies and a reference model economy.

For these reasons Poland and Thailand, both on comparable economical level and yet with completely different management cultures, have been chosen as being representative for fast developing new economies. Switzerland as world's most competitive economy according to the Ernst \& Young (2006) global competitiveness report 2006-2007 (rank number 2), with highest quality of life and work motivation (Schwab, 2009), was chosen as a good reference model.

Gallavin (2004) mentions that web jobs advertisements are a most popular source of jobs propositions especially for ICT workers, as compared to the classified sections of traditional newspapers. Therefore, an analysis of the ICT project managers' vacancies, advertised across 2009 and 2010 on most popular websites in Poland, Switzerland and Thailand, was performed as given in Table 1.

Table 1: Online Jobs Advertisements Portals and No of Identified Vacancies

\begin{tabular}{|l|l|l|}
\hline Country & $\begin{array}{l}\text { No of advertisements } \\
\text { with requirements } \\
\text { related to soft skills }\end{array}$ & Web portal \\
\hline Poland & 78 & $\begin{array}{l}\text { www.infopraca.pl, www.praca.pl, } \\
\text { http://praca.gazetapraca.pl, www.praca.info, } \\
\text { www.pracuj.pl, www.jobpilot.pl, www.jobs.pl }\end{array}$ \\
\hline Switzerland & 61 & $\begin{array}{l}\text { www.jobs.ch, www.jobscout24.ch, } \\
\text { www.jobsuchmaschine.ch, }\end{array}$ \\
\hline Thailand & 80 & $\begin{array}{l}\text { www.nationejobs.com, www.jobsdb.com } \\
\text { http://jobs.monster.co.th, http://th.jobsdb.com }\end{array}$ \\
\hline
\end{tabular}

The main limitation of this part of the study is that it focuses on what the advertisers of the positions chose to include in their advertisements, as opposed to what they actually really apply in the selection process. The advertisements may not include the criteria that the advertisers consider as mandatory, culturally induced and obvious for prospective project managers, which, however, may be vital to them. 
The 38 soft skills that were solicited from 219 advertisements are summarized in Table 2 in columns PL (for Polish advertisements), advertisements) advertisements).

The interpersonal skills, often demanded in advertisement are used either as a synonym for all soft skills or as another term for communication. In the first meaning, it is already comprised in the consideration of this paper, in the second, it underlines the relevance of already listed communication. For this reason this term is not used further in this paper.

Table 2: Survey of Project Managers' Soft Skills

\begin{tabular}{|c|c|c|c|c|c|c|}
\hline Process & Skill name & Journal & Mono & PL & $\mathrm{CH}$ & $\mathrm{TH}$ \\
\hline \multirow{6}{*}{ 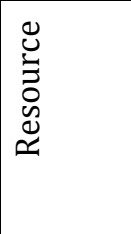 } & Human resource management skills & 1 & 3 & & & \\
\hline & Evaluating personal needs skills & & 1 & & & \\
\hline & Resource allocation skills & 2 & 3 & & & \\
\hline & Resource using skills & & 3 & & & \\
\hline & Recruiting skills & & 1 & 1 & & \\
\hline & Exposing individuals to select & & 1 & & & \\
\hline \multirow{6}{*}{ 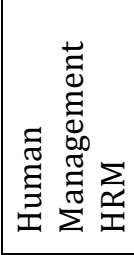 } & Assessing skills & & 1 & & & \\
\hline & Performance evaluations skills & & 2 & & & \\
\hline & Productivity management skills & 1 & & & & \\
\hline & \begin{tabular}{|l|} 
Developing others skills \\
\end{tabular} & 1 & & & & \\
\hline & People development skills & & & 1 & & \\
\hline & Recognizing prior skills & & 1 & & & \\
\hline \multirow{10}{*}{ 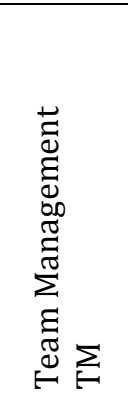 } & Team management skills & 4 & 6 & 19 & 4 & 5 \\
\hline & Team development skills & & 1 & & & \\
\hline & Team building skills & 5 & 7 & 1 & & 3 \\
\hline & People management skills & & 1 & 2 & 5 & 3 \\
\hline & Understanding group dynamics & & 2 & & & \\
\hline & Cross culture management skills & & 1 & & & \\
\hline & Multicultural/multinational & & 1 & 6 & & 5 \\
\hline & Group facilitation skills & 1 & 1 & 1 & & 1 \\
\hline & \begin{tabular}{|ll} 
Relationship & skills, \\
\end{tabular} & 3 & 6 & & 3 & 2 \\
\hline & Coordination skills & 2 & & & 1 & 4 \\
\hline \multirow{3}{*}{ 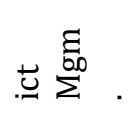 } & Conflict management skills & 13 & 11 & 1 & 4 & 2 \\
\hline & Conflict resolution skills & 13 & 11 & & & \\
\hline & Dealing with conflict skills & & 4 & & & \\
\hline \multirow{18}{*}{ 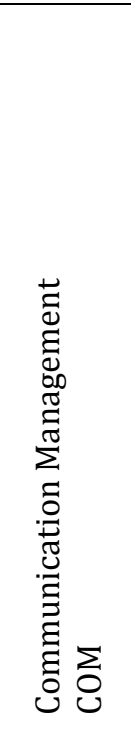 } & Communication skills & 21 & 31 & 50 & 48 & 52 \\
\hline & Choosing the right communication channel & & 1 & & & \\
\hline & Active) listening skills & & 14 & & 1 & \\
\hline & Questioning skills & & 6 & & & \\
\hline & Writing skills & 1 & 4 & & & \\
\hline & Oral skills & 1 & 5 & & & \\
\hline & Talking skills & 1 & 4 & & & \\
\hline & Negotiation skills & 3 & 23 & 10 & 4 & 15 \\
\hline & Network initiation skills & 2 & 1 & & & \\
\hline & Mediation skills & 1 & & & & \\
\hline & Feedback skills & 1 & & & & \\
\hline & Presentation skills & & 9 & 3 & 7 & 18 \\
\hline & Facilitation meetings, mang. Meetings skills & & 6 & & 1 & \\
\hline & Selling skills & & 2 & & & \\
\hline & Marketing skills & & 1 & & & \\
\hline & Data interchange skills & & 2 & & & \\
\hline & Information processing skills & & 2 & & & \\
\hline & Customer orientation skills & & & 15 & 7 & 9 \\
\hline
\end{tabular}




\begin{tabular}{|c|c|c|c|c|c|c|}
\hline \multirow{17}{*}{ 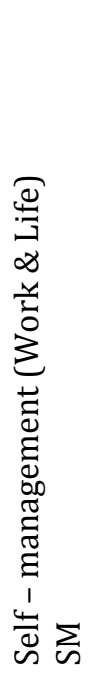 } & Ethical behaviour, ethic & & 2 & & & \\
\hline & Assertiveness & & 2 & 3 & 1 & \\
\hline & Positive attitude & 1 & 1 & & & 2 \\
\hline & Discipline & & 2 & & & \\
\hline & Learning skills, development & & 4 & 3 & & \\
\hline & Self-learning, fast learning, development & & 1 & & 1 & 7 \\
\hline & Personal career development skills & 1 & 1 & & & \\
\hline & Work under stress & & & 12 & & 11 \\
\hline & Stress management skills & 3 & 5 & & 4 & \\
\hline & Time management skills & & 5 & 7 & & 1 \\
\hline & Flexibility & 5 & 4 & 1 & 3 & 1 \\
\hline & Self-motivation skills & & 1 & 4 & 4 & 17 \\
\hline & Team work skills & & 1 & 21 & 10 & 21 \\
\hline & Independence & & & 12 & & \\
\hline & Systematic skills & & & 1 & & \\
\hline & Anger management & & 1 & & & \\
\hline & Self-management & & 1 & & & \\
\hline & Leadership skills (Team leader skills) & 22 & 31 & 9 & 17 & 35 \\
\hline & Understanding personalities skills & & 2 & & & \\
\hline & Training skills & & 1 & & & \\
\hline & Building trust skills & 1 & 1 & & & \\
\hline & Supervising skills & & 4 & 3 & & 2 \\
\hline & Mentoring skills & & 3 & 3 & & 3 \\
\hline & Coaching skills & & 3 & & 1 & 9 \\
\hline & Ability to motivate skills & 10 & 8 & 4 & 3 & \\
\hline & Influencing skills & 2 & 8 & & & \\
\hline & Political skills (to influence organization) & 4 & 2 & & & \\
\hline & Persuasion skills & & 3 & & & 5 \\
\hline & Delegation skills & 4 & 3 & & & \\
\hline & Good judgments skills & & 1 & & & \\
\hline & Ability to take the initiative skills & 1 & 3 & 7 & & 6 \\
\hline & Energize others skills & & 1 & 1 & & \\
\hline & Decision making skills & 1 & 11 & 7 & 1 & 8 \\
\hline & Diplomacy skills & 1 & 1 & & & \\
\hline $\bar{n}$ & Single point of contact skills & & 1 & & & \\
\hline$\frac{\grave{t}}{0}$ & Building team morale skills & 1 & & & & \\
\hline 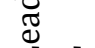 & Directing skills & 1 & & & & \\
\hline$\stackrel{コ}{コ}$ & Achievement orientation skills & & 1 & & & 9 \\
\hline
\end{tabular}

\section{Conclusions: The Awareness Differences between Science and Practice}

Conclusions drawn in this chapter refrain to the state-of-the-art in the scientists and practitioners awareness along the LTimer $^{\text {TM }}$ taxonomy. It is not intended hereafter to analyse in depth the reasons of

the described situation nor the cultural background of the differences or similarities. This is part of the ongoing research and is beyond the scope of this paper.
Table 2 allows general observation, that whereas science considers leadership skills and communication capabilities as most important one, practice calls for communication and leadership in reverse sequence, followed by the team management, first.

Most surprisingly, considering, that people make projects, is the absence of Human Resource Management Skills in published advertisements. Feasible explanation is that the advertisements are mostly posted by a HRM-person, who considers the 
relevant know-how as a discipline reserved for this particular department or person in charge. It is not weighted in accordance with the project needs and not admitted, that in a fact also project manager needs at least some knowledge about this area. Whereas the up-to-date journals and conference publications follow this trend, relevant monographs and standards pay more attention to this subject.

In 73 monographs and publications what is surprisingly low is a number of considered team management skills. It seems that the research is overtaken by practice in this area.

Underrepresented in journals and conference publications are conflict management and self-management skills. Conflict management skills are also not truly considered in advertisements, despite the fact that there is no project, where sooner or later conflict emerges. One possible explanation might be that the advertisement publisher tends to achieve positive image of the prospective job and therefore avoids any admission of potential conflict occurrence. In our conviction, this discrepancy, known to those publishers, is one of the hints that the real evaluation of the candidates might have a hidden agenda, not published in the advertisement. The reasoning might be the cultural heritage, too.

Only recently Self-Management (Work \& Life) related skills have been noticed by research. In job advertisements, corresponding skills have been demanded for some time already. However, the skills named seemed to be based on the experience of earlier project. They are taken out of context. The reasoning why this particular Self-Management skill is chosen is difficult to follow.

True impact of project manager selfmanagement skills on project success seems not to be acknowledged by practice in due manner yet.

Definitely the most comprehensive, what is actually not particularly surprising is the coverage of necessary skills in the monographs and standards. This underlines that despite their inertia in following the newest trends, it may still make sense to apply and work along these publications.

Interesting are the cultural differences reflected in the advertisements. Apparently in Poland, team management skills are those where candidates show the biggest deficit as compared with need. The culturally back-grounded individualism there may be the major source of this deficit. Thailand is here more on the level of Swiss demands already. The team oriented way of working there matches well the project management needs. Contrary, whereas there is apparently sufficient leadership of candidates in Poland, deficit forces the advertisements publishers in Thailand to underline the need of this skill in Thailand.

There is no dramatic difference in demanded skills in other four processes between the three countries. The general conclusions regarding journals, monographs and advertisements hold true here as well.

The detailed differences, an analysis of the possible cultural and political backgrounds, as well as comprehensive coverage of all processes of project management are subject of the ongoing research conducted currently in Switzerland, Poland and Thailand.

\section{Summary}

The focus of the research presented in this paper was to identify and evaluate state-ofthe-art ambiguously in science as well as practice in the area of soft skills considered today as key success factor in the ICT project management. The lack of clear definitions, ambiguity of used terms, and coincidentally selected demanded skills expose broad demand for systematically elaborated approach.

An attempt to introduce certain taxonomy based on L-Timer ${ }^{\text {TM }}$ mental model of project management processes has been drafted. By identifying further the activities of the 
project manager in human factor related processes, the exact skills, helpful in the execution of these activities, may be identified. Conclusions pinpoint the necessity of further profound analysis of cultural, political and possibly other backgrounds of differences and similarities in the current awareness about soft skills needed in ICT project management.

Authors are grateful for having the opportunity to pursue this fascinating research. We acknowledge with gratitude valuable contributions of the reviewers of this paper.

\section{References}

Alam, M., Gale, A., Brown, M. \& Khan, A. I. (2010). "The Importance of Human Skills in Project Management Professional Development," International Journal of Managing Projects in Business, 3 (3). 495 516.

Archibald, R. D. (1992). 'Managing high Technology, Programs and Projects,' John Wiley, NY.

Belbin, M. R. (2010). "Management Teams: Why They Succeed or Fail," Butterworth Heinemann, 3rd ed, UK.

Blaney, J. (1989). 'Managing Software Development Projects,' Proceedings of Project Management Institute Seminar/Simposium Atlanta, October 1989, GA, USA, 410 - 417.

Caupin, G., Knöpfel, H., Morris, P., Motzel, E. \& Pannenbacker, O. (1999). ICB. IPMA Competence Baseline Version 2.0. Satz\&Druck, Bremen: Eigenverlag.

Collett, S. (2006). Hot Skills, Cold Skills. The IT worker of 2010 won't be a technology guru but rather a 'versatilist. Careers: IT Profession 2010, Special Report, [Online], Computerworld, $\quad$ [30.12.2010]. Available:

www.computerworld.com/action/article.d o?command=viewArticleBasic\&articleId $=1$ 12360\&pageNumber $=2$.
Cowie, G. (2003). "The Importance of People Skills for Project Managers," Industrial and Commercial Training, 35(6/7).

Demarco, T. \& Lister, T. (1999). Peopleware: Productive Projects and Teams, 2 edition, Dorset House Publishing Company, USA.

Dewson, S., Eccles, J., Djan Tackey, N. \& Jackson, A. (1987). Measuring Soft Outcomes and Distance Travelled: A Review of Current Practice, The Institute for Employment Studies for DfEE (RR219).

Duncan, W. (1987). 'Get out from under,' Computerworld, 9 March, 1987, 89 - 93.

Ernst \& Young (2006). 'Swiss Attractiveness Survey What Foreign Companies Say,' ERNST \& YOUNG LTD, September 2006.

Flannes, S., Flannes Associates (2004). 'Effective People Skills for the Project Manager: A Requirement for Project Success and Career Advancement,' Proceedings of the Twenty-Ninth Annual SAS® Users Group International Conference. Cary, NC: SAS Institute Inc, 912 May 2004, Montréal, Canada, Paper 131-29.

Gallavin, M., Truex, D. \& Kvasny, L. (2004). "Changing Patterns In IT Skill Sets 19882003: A Content Analysis of Classified Advertisements," The Database for Advances Systems, 35 (1). 64-87.

Gillard, S. (2009). "Soft Skills and Technical Expertise of Effective Project Managers," Informing Science and Information Technology, Volume 6, 723 - 730.

ICB - IPMA Competence Baseline Version 3.0 (2006). IPMA International Project Management Association.

Kerzner, H. (2003). Project Management: A Systems Approach to Planning, Scheduling and Controlling, Wiley, USA.

Lee, D., Trauth, E. \& Farwell, D. (1995). "Critical Skills and Knowledge Requirements of IS Professionals: A Joint 
Academic/Industry Investigation," MIS Quaterly, 19(3). 313 - 340.

Lent, B. \& Pinkowska, M. (2006). "Assessment and Management of the Human Factor Impact on Human Factor Intense Projects - Challenging the Challenge," Proceedings of 20th IPMA World Congress on Project Management, Volume 2, ISBN: 7-111-04703-6, 16-17 October 2006, Shanghai, China, 753-760.

Lent, B. (2003) IT-Projekte lenken - mit System, Friedr. Vieweg \& Sohn Verlag, Wiesbaden, DE.

Lent, B., Keretho, S. \& Pinkowska, M. (2009). 'Efficiency in Project Management Education: Continuous Education Course for Master of Science in IT at Kasetsart University, Bangkok,' Proceedings of Symposium on Project Management ProMAC 2009, ISBN: 978-4-902378-14-6, The Society of Project Management, 28 - 30 October 2009, Bangkok, TH.

Lent, B. (2005). My Dream Project, LentGroup, Bern, $\mathrm{CH}$.

Martin, P. \& Tate, K. (2001). Getting Started in Project Management, Wiley, 1st edition, UK.

Melymuka, K. (2006). 'Want to Kill a Project? Keep Quiet about Problems, Study Finds,' Computerworld, Scottsdale, Ariz, June 07.

Millward Brown (2005). Kompetencje menadżerskie i interpersonalne polskich studentów [Management and interpersonal competencies of polish students]. Prezentacja wyników, Instytut Badania Rynku i Opinii Publicznej SMGKRC, Warsaw, PL.

Moriss, P. W. G. \& Hough, G. H. (1987). The Anatomy of Major Projects, a Study of the Reality of Project Management, John Wiley, UK.

Murch, R. (2001). Basic Skills for Project Managers, Project Management: Best Practices for IT Professionals, Chapter 2, Prentice Hall, New Jersey, USA.
Nash, S. (2004). Vision, Leadership in Project Management 2005 v1, Project Management Institute (PMI). Pennsylvania, USA.

Pant, I. \& Baroudi B. (2008). "Project Management Education: The Human Skills Imperative," International Journal of Project Management 26 (2008). 124-128.

Pinkowska, M. (2006). 'IT Software Project Management: Impact of team cohesiveness on productivity and performance,' Proceedings of IDIMT 2006, ISBN:3-85499049-9, September 2006, Ceskie Budejovice, Czech Republic, 75-90.

Pinkowska, M. (2006). Unpublished work Human Factors in Project Management.

Pinkowska, M. (2010). Human Factor related Processes, Lent.pl project management process research report 2010, Bydgoszcz, PL, 10-24.

Powers, R. F. \& Dickson, G. W. (1973). "MIS Project Management: Myths, Opinions and Reality," California Management Review, 15 (3). 147-156.

Project Management Institute (2004). A Guide to the Project Management Body of Knowledge. Third Edition, CD-ROM, Pennsylvania, USA.

Redmil, F. J. (1990). “Considering Quality in the Management of Software Based Development Projects," Information and Software Technology, 32(1). 18 - 22.

Schwab, K. (2009). The Global Competitiveness Report 2009-2010, World Economic Forum, $\mathrm{CH}$.

Shenhar, A., Renier, J. \& Wideman, R. (1996). 'Improving PM: Linking Success Criteria to Project Type,' Project Management Institute, Calgary, USA.

Simpson, S. (2006). 'The Measurement and Recognition of Soft Factors,' Developing a common standard, University of Surrey, UK. 
Strang, K. D. (2003). "Achieving Organizational Learning across Projects," Proceedings of PMI North America Global Congress 2003, Baltimore, USA, September $23,2003$.

Sukhoo, A., Barnard, A., Eloff, M. M., Van der Poll, J. A. \& Motah, M. (2005). Accommodating Soft Skills in Software project Management, Proceedings of Informing Science and Information Technology Education 2005, 16 - 19 June 2005, Arizona, USA.

Suikki, R., Tromstedt, R. \& Haapasalo, H. (2006). "Project Management Competence Development Framework in Turbulent Business Environment," Technovation, 26(5, 6). 723.

Thieme, R., Tromstedt, R. \& Shin, G. -C. (2003). "Project Management Characteristics and New Product Survival," The Journal of Product Innovation Management, 20(2). 104.

Thomas, J. \& Mengel, T. (2008). “Preparing Project Managers to Deal with Complexity Advanced Project Management Education," International Journal of Project Management, 26(3). 304-315.
Toney, F. \& Powers, R. (1997). Best Practices of Project Management Groups in Large Functional Organisations: Results of the Fortune 500 Project Management Benchmarking Study, Project Management Institute, Upper Darby, PA.

Turner, J. R. (1993). The Handbook of Projects-Based Management, McGraw Hill, USA.

Waterdige, J. (1995). "IT Projects: A Basis for Success," International Journal of Project Management, 13(3). 169 - 172.

Wohlin, C. \& Ahlgren, M. (2005). 'Soft Factors and Their Impact on Time to Market,' Software Quality Journal, No.4, 189-205.

Wong, Z. (2007). "Human Factors in Project Management: Concepts, Tools, and Techniques for Inspiring Teamwork and Motivation," Jossey-Bass, USA. 